\title{
Rehabilitation in Nepal
}

\author{
Raju Dhakal MBBS a, MD and Christine C. Groves MD a,b.
}

a Physical Medicine and Rehabilitation, Spinal Injury Rehabilitation Centre, Post box no 13815, Sanga 011-660847, Nepal;

b Department of Physical Medicine and Rehabilitation, Indiana University School of Medicine, Indianapolis, IN, USA

As a low-income country with a significant burden of disease and frequent natural disasters, the need for rehabilitation in Nepal is significant. Rehabilitation services currently available in Nepal are limited, but the government has recently adopted a 10year action plan to address rehabilitation needs nationwide. Rehabilitation education and training is necessary to provide and retain adequate multidisciplinary rehabilitation providers for current and future needs in Nepal. The implementation of evidence-based recommendations to improve the quality of rehabilitation services and access to rehabilitation is critical to maximize individual and community well-being.

\section{KEY POINTS}

- Rehabilitation services in Nepal are limited, but the government has recently adopted a 10-year action plan to address rehabilitation needs nationwide.

- Rehabilitation education and training are necessary to provide and retain adequate multidisciplinary rehabilitation providers for current and future needs in Nepal.

- Implementation of evidence-based recommendations to improve the quality of rehabilitation services and access to rehabilitation is critical to maximize individual and community well-being.

KEYWORDS: Rehabilitation, Nepal, Low- and middle-income countries, Disability

This is the author's manuscript of the article published in final edited form as:

Dhakal, R., \& Groves, C. C. (2019). Rehabilitation in Nepal. Physical Medicine and Rehabilitation Clinics of North America, 30(4), 787-794. https://doi.org/10.1016/j.pmr.2019.07.004 


\section{INTRODUCTION}

Nepal is a landlocked, mountainous country situated in South Asia between China and India ( Fig. 1 ), with an estimated population of 29.9 million and life expectancy at birth of 70 years. 12 The World Bank categorizes Nepal as a low-income country, with a gross national income per capita of $\$ 790$ and more than $25 \%$ of the population living below the poverty line. 2

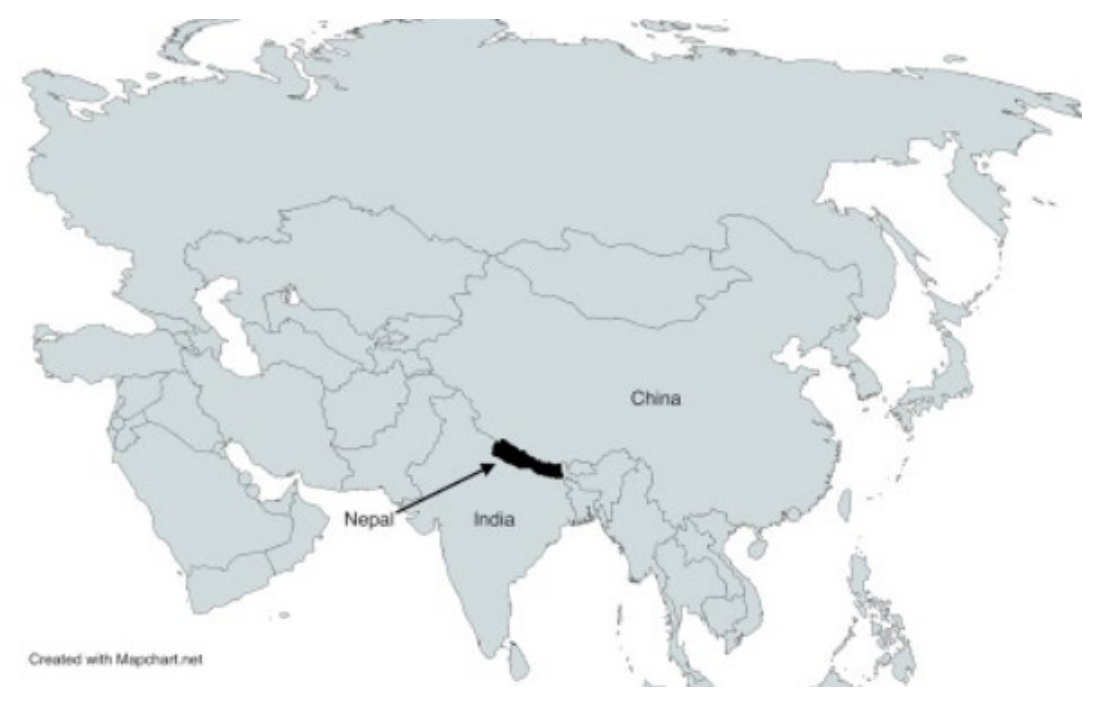

Fig. 1 Geographic location of Nepal.

The term rehabilitation is broadly defined as "a set of interventions designed to optimize functioning and reduce disability in individuals with health conditions in interaction with their environment." 3 Thus, rehabilitation extends to many different specialties and sectors of society. For the purpose of this article, therefore, we specifically focus on medical rehabilitation, including physical medicine and rehabilitation physicians; therapy, including physiotherapy, occupational therapy, and speech and language conditions; and assistive devices.

In addition, rehabilitation is needed and used by a wide variety of individuals, ranging from those with acute injuries who recover fully to those with chronic medical conditions and long-term disabilities. This article specifically focuses on rehabilitation that addresses physical impairments and the resultant hindrances that affect an individual's full and effective participation in society, as defined by the Convention on the Rights of Persons with Disabilities (CRPD). 4 Notably, we do not include impairments, disabilities, and 
rehabilitation services related to mental and hearing/vision impairments, which are themselves enormous fields beyond the scope of this article.

The objectives of this article are to:

- Summarize known data pertaining to the current need for rehabilitation in Nepal.

- Review the present state of rehabilitation services in Nepal.

- Recommend next steps to further develop rehabilitation services appropriate to the needs and context of Nepal.

\section{NEED FOR REHABILITATION}

There have been no comprehensive rehabilitation needs assessments completed in Nepal. However, given that more than $90 \%$ of the causes of the world's burden of disease may benefit from rehabilitation services, the potential needs are significant. 5 Here, we present global and national data addressing both disability and health conditions commonly treated by rehabilitation providers.

The World Health Organization (WHO) estimates that approximately 1 billion people, or $15 \%$ of the global population, are living with some form of disability. 6 Furthermore, disability prevalence is higher in low- and middle-income countries such as Nepal. 6 As the aging population increases globally, the disability trend is also expected to increase. 7 In addition, a recent prolonged civil war (1996-2006) and frequent natural disasters, including major earthquakes in 2015, have also led to increased impairments and disability in Nepal.

During Nepal's 2011 census, 2\% of the country's population reported some kind of disability, defined as the following: "physical disability, blind and low vision, deaf and hard of hearing, deaf-blind, speech problem, mental illness, intellectual disability, and multiple disability." 8 Of these, physical disability accounted for more one-third of the reported disabilities. Following this report, the Central Bureau of Statistics recognized the potential for underreporting of disability during the census and has called for large-scale, dedicated household surveys to be conducted to provide better nationwide statistics on disability. 
More than half of the individuals with disabilities in Nepal are of economically productive age (15-59 years), and disabilities are similarly prevalent in urban and rural areas. 8

According to the Institute of Health Metrics and Evaluation, low back pain is the top cause of disability in Nepal, and cardiovascular disease causes the most disability-adjusted life years (DALYs). 1 Nepal's most common causes of disability and DALYs are listed in Box 1 and Table 1 , respectively. Although population-based injury data are limited, hospitalbased surveillance demonstrates that the most common causes of injuries include falls, road traffic injuries, and burns. 9

\section{BOX 1}

Health problems causing the most disability in Nepal, in order of rank

Data from Viz Hub. Available at: hittp:l/vizhub.healthdata.orglgbd-compare.

- 1. Cardiovascular disease

- 2. Maternal and neonatal

- 3. Chronic respiratory

- 4. Respiratory infections and tuberculosis

- 5. Musculoskeletal disorders

- 6. Neoplasms

- 7. Mental disorders

- 8. Neurologic disorders

- 9. Enteric infections

- 10. Transport injuries 


\section{Table 1}

Top 10 causes of disability-adjusted life years: Nepal 2017

Data from Viz Hub. Available at: http://vizhub.healthdata.org/gbd-compare.

\begin{tabular}{|l|l|l|}
\hline Rank & Cause & Rate per 100,000 \\
\hline 1 & Cardiovascular disease & 3859 \\
\hline 2 & Maternal and neonatal & 3267 \\
\hline 3 & Chronic respiratory & 2456 \\
\hline 4 & Respiratory infections and tuberculosis & 1870 \\
\hline 5 & Musculoskeletal disorders & 1684 \\
\hline 6 & Neoplasms & 1525 \\
\hline 7 & Mental disorders & 1503 \\
\hline 8 & Neurologic disorders & 1355 \\
\hline 9 & Enteric infections & 1246 \\
\hline 10 & Transport injuries & \\
\hline
\end{tabular}

Access to health care in Nepal is limited. According to the Nepal Demographic and Health Survey completed in 2016, $11 \%$ of households nationwide have to travel more than 1 hour to reach the nearest government health facility. This percentage disproportionately affects more mountainous regions and poorer households. 10 Looking at rehabilitation services specifically, a recent systematic review of access to rehabilitation for people with disabilities in low- and middle-income countries demonstrated low coverage in general. 11 The authors also identified barriers to rehabilitation including the following: distance to service, availability/cost of transportation, affordability of services, and knowledge and attitude factors specific to the service. 11

The current state of rehabilitation in Nepal

\section{INSTITUTIONS}

At present, there is no government rehabilitation hospital. Although some acute hospitals offer inpatient physiotherapy services, none have dedicated acute rehabilitation units, and none employ physical medicine and rehabilitation consultants. 
International nongovernmental organizations (INGOs) and local nongovernmental organizations (NGOs) have played vital roles in developing rehabilitation institutions in Nepal. Three hospitals provide most of the inpatient rehabilitation services for the entire country.

Green Pastures Hospital was originally established in 1957 by the International Nepal Fellowship as a leprosy hospital, and services were subsequently expanded to include individuals with spinal cord injury ( $\mathrm{SCl})$, stroke, and traumatic brain injury in the late 1990s. Staff training at the time of expansion was supported and provided by international partners. 12 Currently Green Pastures has 40 inpatient rehabilitation beds, 20 for individuals with leprosy and 20 for individuals with other rehabilitation needs.

The Hospital for Rehabilitation and Disabled Children was conceived by a Nepali orthopedic surgeon, Professor Doctor Ashok K. Banskota, who began offering services to the disabled poor in the 1980s. The center was initially supported by INGOs and is now run by a Nepali NGO. The center has 100 inpatient beds, sees more than 25,000 outpatient visits annually, and runs satellite clinics as part of a comprehensive communitybased rehabilitation (CBR) program.

The concept of a Spinal Injury Rehabilitation Center (SIRC) began when a prominent Nepali journalist, Mr Kanak Mani Dixit, sustained a fall-related SCI in 2001 while trekking in the mountains. Mr Dixit, along with a group of colleagues and friends, established a local NGO that founded SIRC in 2002, now Nepal's largest SCI inpatient rehabilitation center. SIRC has 51 inpatient SCI beds and has recently expanded services to include 10 stroke and traumatic brain injury beds. SIRC provides inpatient rehabilitation for approximately 300 individuals with $\mathrm{SCl}$ per year and provides outpatient care, home follow-up visits, community outreach programs, and a residential vocational rehabilitation program.

\section{PROVIDERS}

The rehabilitation workforce is limited in Nepal. There are no training programs for medical doctors to specialize in the internationally recognized field of physical medicine 
and rehabilitation (PM\&R). At present, only one Nepali PM\&R doctor is registered with the Nepal Medical Council (NMC) and practicing in the country.

In Nepal, there is 1 physiotherapy school at Kathmandu University of Medical Sciences, which offers a bachelor's degree in physiotherapy. Individuals interested in postgraduate degrees must pursue these studies abroad. Currently, 1524 physiotherapist in different specialization and in different levels are registered with Nepal Health Professional Council (NHPC).

A bachelor's degree in audiology, speech, and language pathology is available through the Institute of Medicine with affiliation to Tribhuvan University; however, only 75 speech and hearing individual providers are registered with NHPC in the entire country.

There are no formal training programs for occupational therapy in Nepal. Although the exact number of occupational therapists in Nepal is unknown, 9 institutions/organizations offer occupational therapy services throughout the country.

Training in prosthetics, orthotics, and/or assistive device technology is also not available in Nepal. 24 individuals with training on the use of prosthetics and orthotics training are registered with NHPC throughout the country.

These obvious workforce limitations have sweeping implications. As the WHO World Report on Disability states, "Unmet rehabilitation needs can delay discharge, limit activities, restrict participation, cause deterioration in health, increase dependency on others for assistance, and decrease quality of life. These negative outcomes can have broad social and financial implications for individuals, families, and communities." 6

\section{TECHNOLOGY}

The availability of assistive devices, including mobility aids, is inadequate; most of them must be imported. Many individuals and institutions rely on outside organizations and donations for these devices. No local manufacturers exist in Nepal to meet the needs of people with impairments and disability. 


\section{POLICY}

The importance of and the need for rehabilitation was brought to the forefront of planning and policy making immediately after the 2015 earthquakes in Nepal. According to the Nepal Government's new Policy, Strategy, and Ten Years Action Plan on Disability Management, 13 finalized in 2016, within 5 years, adequate disability and rehabilitation human resources should be produced and posts created for primary disability identification, management, referral, and counseling. PM\&R physicians are included in the required posts. Furthermore, within 10 years every region and state should have at least one fully equipped rehabilitation center and established orthotics/prosthetics workshop. This new policy reflects a commitment from the Nepali government, which ratified the CRPD in 2010, and marks a dramatic improvement in attention and support given to caring for individuals with disabilities and expanding rehabilitation services throughout the country.

\section{FUTURE DIRECTION}

Given the significant need for rehabilitation in Nepal and the extremely limited services currently offered, implementation of the Policy, Strategy, and Ten Years Action Plan on Disability Management is imperative. In addition, specific focus should be given to establishing and improving training and education opportunities for rehabilitation providers and broader implementation of multi-/interdisciplinary rehabilitation in health systems nationwide. We focus strongly on developing and improving training opportunities in Nepal, because a recent survey carried out by the International Labor Organization found that nearly $40 \%$ of Nepali health care students planned to migrate abroad for further education. 14 Although this study focuses only on medical and nursing students, we have personally witnessed similar trends among physiotherapists at our center.

\section{REHABILITATION EDUCATION AND TRAINING}

We believe that PM\&R specialization should be made available to doctors in Nepal as soon as possible. Multiple international partners are ready and willing to provide educational support in the initial stages of PM\&R training, and indeed are necessary given 
the current lack of PM\&R physicians. Nepal could and should institute a 3-year PM\&R residency with a standardized curriculum that covers the breadth and depth of the field. This curriculum would apply at multiple teaching sites in the country to provide, at a minimum, clinical rotations with academic preceptors in the following areas: $\mathrm{SCl}$ rehabilitation, stroke and brain injury rehabilitation, orthopedic rehabilitation, pediatric rehabilitation, wound care, burn rehabilitation, prosthetics and orthotics, electrodiagnosis, and musculoskeletal medicine. Contextual needs, such as leprosy rehabilitation, for example, should be considered in curriculum development.

During the initial years of residency training, local faculty in partnership with visiting international faculty would serve as preceptors to ensure evidence-based education throughout the clinical rotations, as well as standardized assessment and professional licensure/registration. As Nepali PM\&R residents graduate and enter independent practice, the regular use of international faculty members can be appropriately phased out and such training will be fully sustained by Nepali PM\&R specialists.

In addition, steps should be taken to increase opportunities for physiotherapists to pursue training at postgraduate level in Nepal. We also strongly urge the Ministry of Health and Ministry of Education to take steps to develop graduate and postgraduate occupational therapy as well as prosthetics and orthotics programs.

\section{HEALTH SYSTEMS}

WHO's recent Rehabilitation in Health Systems recommendations clearly lay out priorities to strengthen rehabilitation in the context of Nepal. ${ }^{3}$ Table 2 presents the strongest evidence-based recommendations made, all of which are at least partially targeted by the government's Action Plan on Disability management. 


\section{Table 2}

WHO recommendations on rehabilitation in health systems

Data from World Health Organization. Rehabilitation in health systems. Available at: http://www.who.int/rehabilitation/rehabilitation_health_systems/en/ . Accessed 5 December 2018.

\begin{tabular}{|l|l|}
\hline Recommendation & Evidence \\
\hline A multidisciplinary rehabilitation workforce should be available & High \\
\hline $\begin{array}{l}\text { Both community and hospital rehabilitation services should be } \\
\text { available }\end{array}$ & Moderate \\
\hline $\begin{array}{l}\text { Hospitals should include specialized rehabilitation units for inpatients } \\
\text { with complex needs }\end{array}$ & Very high \\
\hline
\end{tabular}

Only recommendations with "strong" strength of recommendation are included.

The implementation of these 3 recommendations alone will significantly improve the quality and coverage of rehabilitation services offered throughout Nepal. Unique to our context is the rugged/mountainous terrain. Given this, and the reality that $80 \%$ of the population live in rural communities, providing coordinated CBR services throughout the country is critical. ${ }^{2}$ Currently, there are 50 to 60 CBR programs being implemented by local NGOs and organizations. Twelve of these programs are supported by the Ministry of Women, Children and Social Welfare directly, whereas others are supported by NGOs and INGOs. However, no network exists to link these CBR programs. Strong collaboration and coordination among organizations to maximize CBR provision and coverage throughout the country is imperative and needs to be implemented.

Research in Rehabilitation

There is limited research in PM\&R in the context of Nepal. Most of the available literature is hospital based and descriptive in nature. Population-based studies are needed to fully understand the prevalence of conditions that lead to the need for rehabilitation. Consistent with the WHO's recommendations, research priorities in Nepal should focus on costbenefit analyses of rehabilitation services, rehabilitation access, and measuring the impact of rehabilitation in standardized ways that have been validated in the context of Nepal. ${ }^{3}$ In addition, high-quality interventional studies in Nepal and/or similar contexts are needed to improve and maximize rehabilitation efficacy. 


\section{SUMMARY}

The need for rehabilitation services in Nepal is great. As rehabilitation becomes a more specific focus among stakeholders nationally and globally, now is the time for Nepal to not only plan but also implement evidence-based strategies to provide more comprehensive person-centered rehabilitation that optimizes function and reduces disability. The results will undoubtedly have an impact individuals, families, communities, and indeed the entire country. ${ }^{3}$

Disclosure Statement: The authors have nothing to disclose.

1 Present address: 4204 Ponderosa Boulevard, Indianapolis, IN 46250.

\section{REFERENCES}

1. Institute for Health Metrics and Evaluation : Nepal Country Profile 2018. www.healthdata.org/nepal

2. Country Profile: Nepal. https://data.worldbank.org/country/nepal

3. World Health Organization : Rehabilitation in health systems.

4. United Nations : Convention on the rights of persons with disabilities.

5. Kamenov K., Mills J.A., Chatterji S., et al: Needs and unmet needs for rehabilitation services: a scoping review. Disabil Rehabil 2019; 41: pp. 1227-1237

6. World report on disability. http://www.who.int/disabilities/world_report/2011/en/

7. United Nations : World population ageing.

8. Government of Nepal Central Bureau of Statistics : National population and housing census. 
9. Government of Nepal Ministry of Health : Annual report Department of Health Services 2016/2017. Kathmandu (Nepal): Government of Nepal, 2017.

10. Nepal Demographic and health survey 2016.

11. Bright T., Wallace S., and Kuper H.: A systematic review of access to rehabilitation for people with disabilities in low- and middle-income countries. Int J Environ Res Public Health 2018; 15:

12. Brandsma J.W., Schwarz R.J., Anderson A.M., et al: Transformation of a leprosy hospital in Nepal into a rehabilitation centre: the Green Pastures Hospital experience. Lepr Rev 2005; 76: pp. 267-276

13. Policy, strategy, and ten years action plan on disability management (2073 - 2083). Kathmandu (Nepal): Government of Nepal Leprosy Control Division, 2016.

14. Migration of health workers from Nepal. https://ceslam.org/docs/publicationManagement/ILO_Migration_of_Health_Work ers_from_Nepal.pdf 